\title{
Epidemiology of restaurant-associated foodborne disease outbreaks, United States, 1998-2013
}

\author{
K. M. ANGELO ${ }^{1 *}$, A. L. NISLER ${ }^{2}$, A. J. HALL ${ }^{2}$, L. G. BROWN ${ }^{3}$ AND \\ L. H. GOULD ${ }^{1}$ \\ ${ }^{1}$ Division of Foodborne, Waterborne, and Environmental Diseases, National Center for Emerging and Zoonotic \\ Infectious Diseases, Centers for Disease Control and Prevention, Atlanta, GA, USA \\ ${ }^{2}$ Division of Viral Diseases, National Center for Immunization and Respiratory Diseases, Centers for Disease \\ Control and Prevention, Atlanta, GA, USA \\ ${ }^{3}$ Division of Emergency and Environmental Health Services, National Center for Environmental Health, Centers \\ for Disease Control and Prevention, Atlanta, GA, USA
}

Received 27 July 2016; Final revision 1 September 2016; Accepted 14 September 2016; first published online 18 October 2016

\section{SUMMARY}

Although contamination of food can occur at any point from farm to table, restaurant food workers are a common source of foodborne illness. We describe the characteristics of restaurantassociated foodborne disease outbreaks and explore the role of food workers by analysing outbreaks associated with restaurants from 1998 to 2013 reported to the Centers for Disease Control and Prevention's Foodborne Disease Outbreak Surveillance System. We identified 9788 restaurant-associated outbreaks. The median annual number of outbreaks was 620 (interquartile range 618-629). In 3072 outbreaks with a single confirmed aetiology reported, norovirus caused the largest number of outbreaks $(1425,46 \%)$. Of outbreaks with a single food reported and a confirmed aetiology, fish (254 outbreaks, 34\%) was most commonly implicated, and these outbreaks were commonly caused by scombroid toxin ( 219 outbreaks, $86 \%$ of fish outbreaks). Most outbreaks (79\%) occurred at sit-down establishments. The most commonly reported contributing factors were those related to food handling and preparation practices in the restaurant (2955 outbreaks, 61\%). Food workers contributed to 2415 (25\%) outbreaks. Knowledge of the foods, aetiologies, and contributing factors that result in foodborne disease restaurant outbreaks can help guide efforts to prevent foodborne illness.

Key words: Infectious disease epidemiology, outbreaks, public health.

\section{INTRODUCTION}

Foodborne illness caused by a known pathogen causes an estimated $9 \cdot 4$ million illnesses, 56000 hospitalizations, and over 1300 deaths annually in the United States [1]. Over $90 \%$ of these illnesses are caused by

\footnotetext{
* Author for correspondence: K. M. Angelo, DO, MPH-TM, 1600 Clifton Road NE, Atlanta, GA 30333, USA.

(Email: kangelo@cdc.gov)
}

15 major pathogens, including various viruses, bacteria, and parasites, but most commonly norovirus and Salmonella enterica $[2,3]$.

Annually, over 800 foodborne disease outbreaks are reported to the Centers for Disease Control and Prevention (CDC) and most commonly occur in a restaurant setting [2]. In 2013, 51\% of single-setting foodborne disease outbreaks were caused by food prepared in a restaurant [4]. Americans eat at restaurants an average of five times weekly [5] and it is estimated 
that $47 \%$ of every dollar spent on food in 2015 was spent at a restaurant [6].

The U.S. Food and Drug Administration (FDA) provides guidelines designed to prevent foodborne disease in restaurant settings; states are responsible for adopting and enforcing restaurant food-safety regulations. These guidelines address the standards for personnel management and employee health, food-safety practices, equipment storage and cleanliness, waste disposal, physical facility optimization to avoid contamination with pathogens, and poisonous material handling and storage [7]. Contamination of food served in a restaurant can occur at any point from farm to table. The guidelines aim to minimize restaurants' role in foodborne illness.

The study objective was to describe the characteristics of restaurant-based foodborne disease outbreaks, identify outbreak contributing factors, and examine the role of food workers in these outbreaks. Results of this analysis can help guide efforts to prevent foodborne illness.

\section{MATERIALS AND METHODS}

CDC collects foodborne disease outbreak reports from state and local health departments through the Foodborne Disease Outbreak Surveillance System (FDOSS) [8]. The information collected for each outbreak includes year, month, state, number of illnesses, hospitalizations and deaths, confirmed aetiology, implicated food, settings where food was prepared, and contributing factors.

We reviewed foodborne disease outbreaks that occurred during 1998-2013 in which a restaurant was the only place where food was prepared. We analysed implicated food categories, aetiology, restaurant type, and factors contributing to outbreak occurrence.

Implicated foods were categorized using the Interagency Food Safety Analytics Collaboration's (IFSAC) scheme [9]. Implicated foods that contained ingredients belonging to more than one category were classified as 'complex' when the food category responsible for illness could not be determined. For most pathogens, an aetiology was defined as confirmed if the organism was detected in samples from two or more ill persons, or in an epidemiologically implicated food(s). For marine and other toxins, confirmation requires a clinically compatible illness in two or more ill persons who ate an implicated food (e.g. as with the distinct clinical syndromes of botulism, scrombroid toxin, or heavy metals) [10, 11].
Aetiologies not meeting the criteria were classified as suspect; these suspect aetiologies included toxinmediated illness (e.g. Bacillus cereus, Clostridium perfringens, Staphylococcus aureus enterotoxin) and uncommon aetiologies (e.g. Trichinella, Cyclospora, pesticides) in which laboratory confirmation was only performed for a single ill person or illness was identified through clinical presentation and/or epidemiological risk factors without laboratory testing. Only confirmed aetiologies were included in aetiology analyses. The restaurant type (i.e. sit-down, fast-food, other) was reported starting in 2009. Contributing factors, or reasons for contamination, were grouped into one of four categories for analysis: food worker health and hygiene, food contamination before arrival at the restaurant, food handling and preparation practices in the restaurant, and other factors (Appendix A). Because more than one contributing factor could be reported for an outbreak, an outbreak could be included in more than one contributing factor category. Food workers were implicated if a contributing factor indicating lapses in food worker health and hygiene (e.g. bare-hand contact with food) was reported or if a food worker was explicitly implicated as the cause.

The Wilcoxon test was used to compare the median number of ill persons in outbreaks. All analysis was performed using SAS v. 9.3 (SAS Institute Inc., USA).

\section{RESULTS}

Of 17445 outbreaks reported during 1998-2013, 9788 $(56 \%)$ outbreaks involved food prepared in a restaurant (Appendix B), resulting in 124608 illnesses, 4427 hospitalizations, and 32 deaths. There were a median of 620 outbreaks annually [interquartile range (IQR) 618-629], resulting in 3151 to 11426 illnesses each year. The median outbreak size was five persons (IQR 3-12). The largest number of restaurant-associated outbreaks were reported from Florida (1742 outbreaks, 18\%), California (1289 outbreaks, 13\%), and Ohio (666 outbreaks, 7\%). The annual number of restaurant-associated outbreaks and the percentage of all outbreaks linked to restaurants declined from $2000(884,63 \%)$ to 2013 (431, 52\%) (Fig. 1).

\section{Implicated foods}

A food was implicated in $4102(42 \%)$ outbreaks. Of these, $1775(43 \%)$ had a food that could be assigned to a single category, most commonly fish (387 


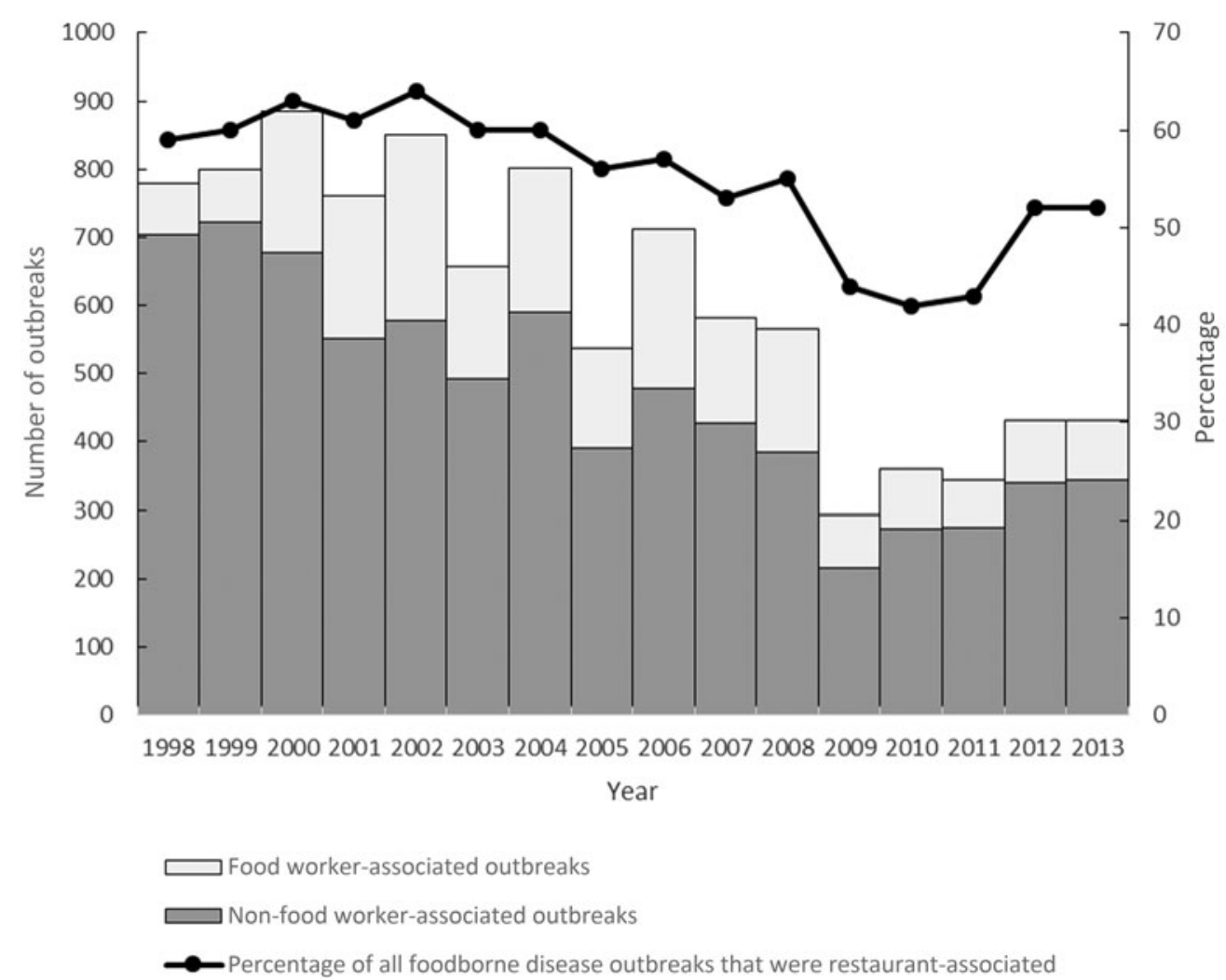

Fig. 1. Number of restaurant-associated foodborne disease outbreaks and percentage of all foodborne disease outbreaks, by year, Foodborne Disease Outbreak Surveillance System, 1998-2013. $\square$, Number of foodworker-associated outbreaks; $\square$, number of non-foodworker-associated outbreaks; $\rightarrow$, percentage of all foodborne disease outbreaks that were restaurant-associated.

outbreaks, 33\%), beef (314 outbreaks, $27 \%$ ), chicken (239 outbreaks, 20\%), and molluscs (147 outbreaks, 13\%) (Table 1).

\section{Aetiology}

A single confirmed aetiology was reported in 3072 (31\%) outbreaks; norovirus caused the most outbreaks $(1425,46 \%)$ and outbreak-associated illnesses (52630, $42 \%$ ) (Table 2). The median number of ill persons in norovirus outbreaks was 14 (IQR 7-26). Most deaths were due to Salmonella infections (5/23 deaths with a reported aetiology, 22\%).

Other common confirmed aetiologies were Salmonella enterica (728 outbreaks, 24\%), scombroid toxin (238 outbreaks, 8\%), C. perfringens (123 outbreaks, 4\%), Shiga toxin-producing Escherichia coli (117 outbreaks, $4 \%$ ), and Shigella (76 outbreaks, $2 \%$ ) (Table 2). The percentage of restaurant-associated outbreaks caused by norovirus increased during the study period, comprising $15 \%$ of outbreaks in 1998 and $40 \%$ of outbreaks in 2013. In contrast, the second most common confirmed aetiology, Salmonella, comprised $33 \%$ of outbreaks in 1998 and 31\% in 2013 (Fig. 2).

Of the 750 outbreaks with a confirmed aetiology linked to a single food category, the most common pairs were scombroid toxin in fish (219 outbreaks, $29 \%$ ), S. enterica in eggs (66 outbreaks, 9\%), Vibrio spp. in molluscs (33 outbreaks, 4\%), C. perfringens in beef ( 25 outbreaks, $3 \%)$, and norovirus in vegetable row crops (22 outbreaks, $3 \%$ ).

\section{Restaurant type}

Of the 1859 single restaurant-associated outbreaks reported from 2009 to $2013,1463(79 \%)$ were at sitdown dining establishments and $246(13 \%)$ were at fast-food establishments. Of the 804 outbreaks with both a restaurant type and a confirmed aetiology, norovirus outbreaks associated with sit-down restaurants were most common (321, 40\%) (Table 3). Of the 278 outbreaks with both an implicated food category and information on restaurant type available, fish (57 outbreaks), molluscs (38 outbreaks), and chicken 
Table 1. Foods implicated in restaurant-associated foodborne disease outbreaks, Foodborne Disease Outbreak Surveillance System, 1998-2013 ( $n=1775)$

\begin{tabular}{lllll}
\hline \hline Food category & $\begin{array}{l}\text { Outbreaks } \\
n(\%)\end{array}$ & $\begin{array}{l}\text { Illnesses } \\
n(\%)\end{array}$ & $\begin{array}{l}\text { Hospitalizations } \\
n(\%)\end{array}$ & $\begin{array}{l}\text { Deaths } \\
n(\%)\end{array}$ \\
\hline Fish & $387(22)$ & $1532(7)$ & $79(6)$ & $0(0)$ \\
Beef & $314(18)$ & $2831(12)$ & $151(11)$ & $3(38)$ \\
Chicken & $239(13)$ & $2274(10)$ & $99(7)$ & $1(13)$ \\
Molluscs & $147(8)$ & $786(3)$ & $32(2)$ & $0(0)$ \\
Grains/beans & $108(6)$ & $602(3)$ & $11(1)$ & $0(0)$ \\
Vegetable row crops & $97(6)$ & $3378(15)$ & $236(17)$ & $0(0)$ \\
Pork & $94(5)$ & $1173(5)$ & $132(10)$ & $1(12)$ \\
Eggs & $85(5)$ & $1770(8)$ & $186(13)$ & $0(0)$ \\
Crustaceans & $64(4)$ & $537(2)$ & $7(0 \cdot 5)$ & $0(0)$ \\
Fruits & $48(3)$ & $2321(10)$ & $46(3)$ & $1(12)$ \\
Seeded vegetables & $44(2)$ & $2437(11)$ & $190(14)$ & $0(0)$ \\
Root/underground & $38(2)$ & $387(2)$ & $7(0 \cdot 5)$ & $0(0)$ \\
Dairy & $34(2)$ & $662(3)$ & $31(2)$ & $0(0)$ \\
Turkey & $33(2)$ & $716(3)$ & $99(7)$ & $2(25)$ \\
Other* & $43(2)$ & $1456(6)$ & $78(6)$ & $0(0)$ \\
Total & 1775 & 22862 & 1384 & 8 \\
\hline \hline
\end{tabular}

* Other outbreak food categories were fungi $(n=5)$, game $(n=2)$, herbs $(n=10)$, nuts/seeds $(n=1)$, oils/sugars $(n=2)$, other meat or poultry not otherwise specified $(n=10)$, and sprouts $(n=13)$.

(26 outbreaks) were the most common foods associated with sit-down restaurants, and vegetable row crops and sprouts were most common in fast-food restaurants (five outbreaks each) (Table 3). Certain foods were more frequently implicated in sit-down than fast-food restaurants, including eggs ( $8 \%$ of outbreaks in sit-down dining restaurants $v s .0 \%$ in fast-food restaurants), pork ( $8 \% v$ vs. $4 \%$ ), molluscs $(18 \% v s .0 \%)$, chicken $(12 \%$ vs. $4 \%)$, and fish ( $27 \%$ vs. $16 \%)$.

\section{Outbreak contributing factors}

In the 9788 restaurant-associated outbreaks, 4941 $(50 \%)$ outbreaks contained information on at least one contributing factor, with a total of 6907 contributing factors recorded (Appendix A). The most common were those related to food handling and preparation practices in the restaurant (2995 outbreaks, 61\% of those with any contributing factor recorded) followed by those related to food worker health and hygiene (2344 outbreaks, 47\%). Factors related to food contamination before reaching the restaurant (761 outbreaks, $15 \%$ ) were less common.

The most common outbreak contributing factors related to food handling and preparation practices in the restaurant were improper adherence of an approved plan to use time as a public health control (962 outbreaks, 32\%), inadequate or insufficient thawing of frozen products leading to the proliferation of pathogens (957 outbreaks, 32\%), and crosscontamination by a non-food handler who was suspected of being infectious (954 outbreaks, 32\%).

In the 1875 outbreaks with a confirmed aetiology and contributing factor information available, Salmonella was the most common confirmed aetiology in outbreaks in which food contamination before entering the restaurant was cited as a contributing factor [157 (33\%) outbreaks of 481 ] and food handling and preparation practices in the restaurant was cited as a contributing factor [341 (40\%) of 861 outbreaks]. Norovirus was the most common confirmed aetiology in outbreaks in which contamination related to food worker health and hygiene was cited as a contributing factor [706 (71\%) of 997 outbreaks] and other contamination methods [68 (27\%) of 253 outbreaks].

Scombroid toxin in fish was the most common food-aetiology pair in outbreaks with a confirmed aetiology related to contamination of food before reaching the restaurant (136 outbreaks), outbreaks related to food handling and preparation practices occurring within the restaurant (75 outbreaks), and outbreaks related to other contributing factors (33 outbreaks). Norovirus in vegetable row crops was the most common food-aetiology pair in outbreaks with a confirmed aetiology related to food worker health and hygiene (15 outbreaks). 
Table 2. Aetiologies in restaurant-associated foodborne disease outbreaks, Foodborne Disease Outbreak Surveillance System, 1998-2013

\begin{tabular}{lllll}
\hline \hline Aetiology & $\begin{array}{l}\text { Confirmed } \\
n(\%)\end{array}$ & $\begin{array}{l}\text { Suspected } \\
n(\%)\end{array}$ & $\begin{array}{l}\text { Total } \\
n(\%)\end{array}$ & $\begin{array}{l}\text { Median outbreak } \\
\text { size (IQR)* }\end{array}$ \\
\hline Norovirus & $1425(46)$ & $1178(48)$ & $2603(47)$ & $14(7-26)$ \\
Salmonella enterica & $728(24)$ & $93(4)$ & $821(15)$ & $9(4-20)$ \\
Scombroid toxin & $238(8)$ & $61(3)$ & $299(5)$ & $2(2-3)$ \\
Clostridium perfringens & $123(4)$ & $240(10)$ & $363(6)$ & $11(6-24)$ \\
Shiga toxin-producing E. coli & $117(4)$ & $2(0)$ & $119(2)$ & $8(4-19)$ \\
Shigella spp. & $76(2)$ & $9(0)$ & $85(2)$ & $10(5-26)$ \\
Staphylococcus aureus enterotoxin & $74(2)$ & $287(12)$ & $361(7)$ & $10(4-20)$ \\
Campylobacter spp. & $65(2)$ & $37(2)$ & $102(2)$ & $6(3-11)$ \\
Hepatitis virus & $50(2)$ & $1(0)$ & $51(1)$ & $9(6-32)$ \\
Bacillus cereus & $47(2)$ & $298(12)$ & $345(6)$ & $6(3-11)$ \\
Vibrio spp. & $47(2)$ & $36(1)$ & $83(2)$ & $4(2-5)$ \\
Ciguatoxin & $26(1)$ & $7(0)$ & $33(1)$ & $4(2-6)$ \\
Other $\dagger$ & $47(2)$ & $207(8)$ & $254(4)$ & n.a. \\
Total & 3072 & 2456 & 5528 & \\
\hline \hline
\end{tabular}

n.a., Not applicable.

* Interquartile range in outbreaks with confirmed aetiologies.

$\dagger$ Other confirmed aetiologies were amnesic shellfish poisoning $(n=1)$, astrovirus $(n=1)$, Cyclospora $(n=9)$, Enterococcus $(n=1)$, Giardia $(n=6)$, heavy metals $(n=2)$, Listeria $(n=5)$, monosodium glutamate $(n=1)$, other chemicals and toxins not otherwise specified $(n=10)$, pesticides $(n=3)$, rotavirus $(n=1)$, sapovirus $(n=2)$, Trichinella $(n=1)$, and Yersinia $(n=2)$.

\section{Implication of food workers}

Food workers were implicated as the source in 2344 $(24 \%)$ of the 9788 outbreaks. The median size of outbreaks in which a food worker was implicated was eight ill persons (IQR 4-20), compared to a median of four (IQR 2-9) for all other outbreaks $(P<0 \cdot 001)$.

A single food category was identified in $1372(59 \%)$ of 2344 outbreaks involving a food worker, most commonly beef (62 outbreaks), chicken (45 outbreaks), and vegetable row crops (41 outbreaks). Most outbreaks where food workers were implicated occurred in sit-down restaurants [274 (82\%) out of 336 outbreaks since 2009].

Information was available on a confirmed aetiology for 1131 of the 2344 outbreaks involving food workers. Norovirus was the most frequent cause (794 outbreaks, $70 \%$ of outbreaks involving a food worker), followed by S. enterica (191 outbreaks, 17\%), and Staphylococcus aureus enterotoxin (35 outbreaks, 3\%). The Salmonella serotypes most commonly implicated in food workerassociated outbreaks were Enteritidis (60 outbreaks), Typhimurium (26 outbreaks), Heidelberg (18 outbreaks), and Newport (14 outbreaks).

\section{DISCUSSION}

This study highlights the significant burden of foodborne disease outbreaks that occur in restaurants in the United States. Over half of all foodborne disease outbreaks reported to the CDC from 1998 to 2013 involved a restaurant setting.

We found that factors related to food handling and preparation practices in restaurants, including inadequate thawing resulting in pathogen proliferation and cross-contamination were the most frequent contributors to restaurant outbreaks. Food workers have reported that obstacles such as sink accessibility and clean cutting board availability, time demands, restaurant management and coworker influence, and lack of food-safety training and procedures, all negatively impact their ability to safely prepare foods in accordance with guidelines and regulations [12] and are likely reasons for food preparation lapses. Of these outbreaks with contributing factors related to food handling and preparation in the restaurant, Salmonella was the most common confirmed aetiology. This likely indicates that food enters the restaurant contaminated (i.e. poultry contaminated with Salmonella) and proper procedures are not followed to eliminate this organism once in the restaurant. Although the FDA Food Code was established to minimize five major risk factors in restaurant-associated foodborne illness, including improper holding temperatures, inadequate cooking, contaminated equipment, obtaining food from unsafe sources, and poor personal 


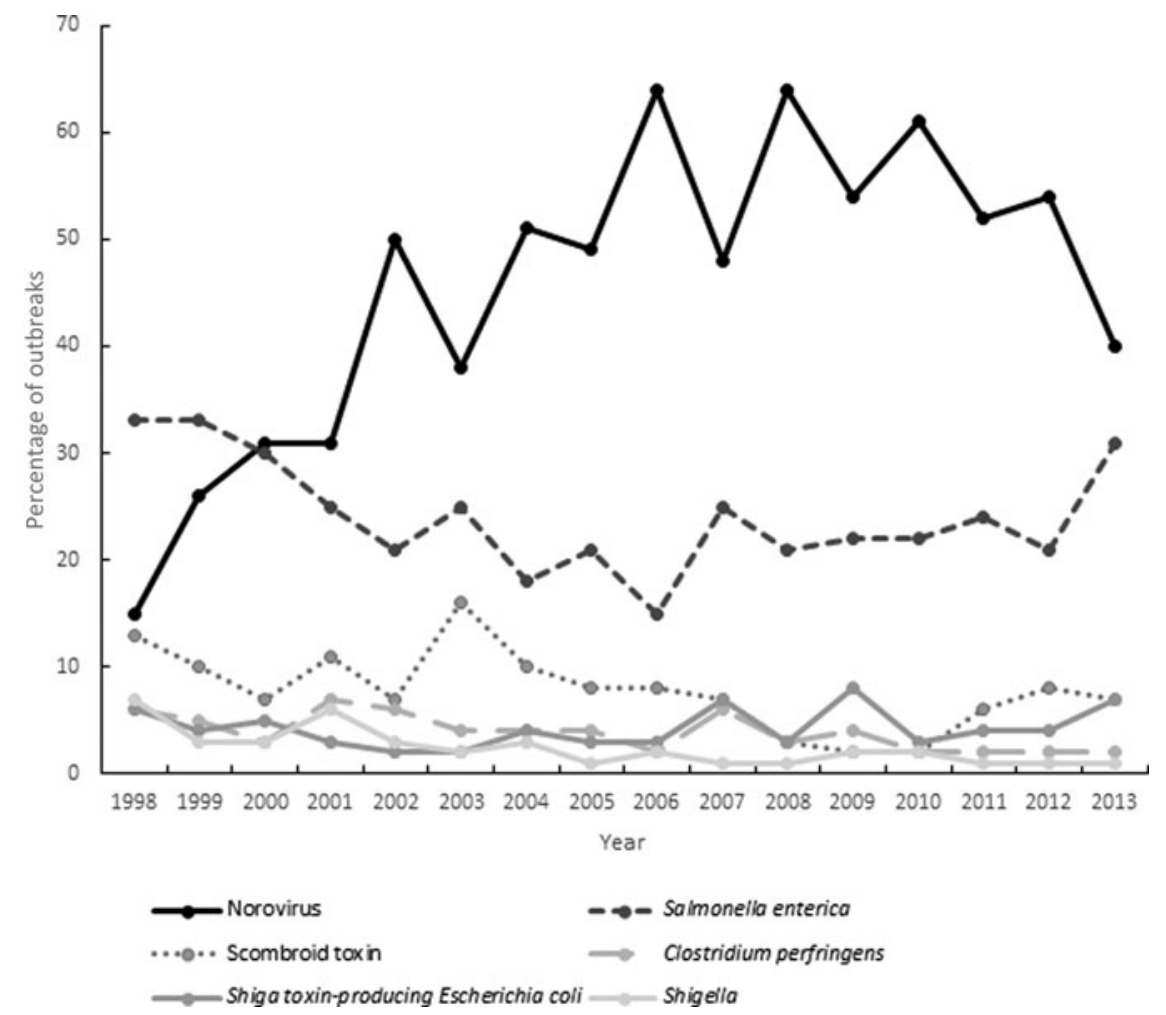

Fig. 2. Percentage of restaurant-associated outbreaks caused by the most common confirmed aetiologies, by year, Foodborne Disease Outbreak Surveillance System, 1998-2013.

hygiene [7], obstacles to implementing and following these guidelines must be addressed.

We found that food workers contributed to a quarter of all restaurant-associated outbreaks, and outbreaks associated with food workers tended to be larger than others. This underscores the role of food worker health and hygiene and safe food preparation practices in restaurant settings in foodborne illness prevention. Food workers can contribute to food contamination by failing to adhere to safe food preparation time and temperature guidelines, directly introducing pathogens while preparing food when ill, or cross-contaminating ready-to-eat foods or cooked foods with raw food [12-14]. A recent survey of restaurant food workers found that most lacked knowledge about foodborne disease prevention, including correct handwashing technique, proper food storage, adequate meat temperatures, and how to tell if food has gone bad [14]. Food workers report not always wearing gloves while handling ready-to-eat foods and not changing gloves in between handling raw meat and ready-to-eat foods [15]. Inadequate handwashing is a well-established method for spreading illness [7]; food workers are less likely to practice appropriate handwashing when they are busy [14].
In an observational study assessing food workers' handwashing frequency, hands were washed only 39 $(7 \%)$ of the 582 times they should have been washed. Hands were not washed after touching aprons, and rarely when changing tasks or handling different food products. Moreover, compliance with the FDA Food Code handwashing guideline was extremely low $(5 \%)$ [16]. A survey from 2010 revealed that close to $88 \%$ of restaurant workers do not receive paid sick days and over $63 \%$ had cooked or served food while sick [17]. Moreover, one-third of restaurants do not have clear policies about when to allow a sick food worker to work and $20 \%$ of food workers went to work while ill at least once in the previous year $[5,17]$.

An implicated food was not reported in half of restaurant-associated outbreaks. This is in part because linking a food to an outbreak is often difficult, as it requires identifying a common food exposure. Ill persons may have many common exposures, making it difficult to distinguish which food item caused the outbreak. In outbreaks in which an implicated food was identified, half were linked to complex foods in which an ingredient in a single food category could not be identified. This is likely due to the 
Table 3. Number of restaurant-associated foodborne disease outbreaks by food, aetiology, and restaurant type, Foodborne Disease Outbreak Surveillance System, 2009-2013

\begin{tabular}{|c|c|c|c|c|}
\hline & \multicolumn{3}{|c|}{ Restaurant type, $n(\%)$} & \multirow[b]{2}{*}{ Total } \\
\hline & Sit-down & Fast-food & Other* & \\
\hline \multicolumn{5}{|l|}{ Confirmed aetiology } \\
\hline Norovirus & $321(51)$ & $56(51)$ & $41(65)$ & 418 \\
\hline Salmonella enterica & $151(34)$ & $29(27)$ & $14(22)$ & 194 \\
\hline $\begin{array}{l}\text { Clostridium } \\
\text { perfringens }\end{array}$ & $17(3)$ & $1(1)$ & $1(2)$ & 19 \\
\hline Scombroid toxin & $36(6)$ & $4(4)$ & $1(2)$ & 41 \\
\hline $\begin{array}{l}\text { Shiga } \\
\text { toxin-producing } E \text {. } \\
\text { coli }\end{array}$ & $27(4)$ & $9(8)$ & $1(2)$ & 37 \\
\hline Campylobacter spp. & $20(3)$ & $0(0)$ & $1(2)$ & 21 \\
\hline Vibrio spp. & $16(3)$ & $0(0)$ & $1(2)$ & 17 \\
\hline Ciguatoxin & $10(2)$ & $0(0)$ & $1(2)$ & 11 \\
\hline Shigella spp. & $6(1)$ & $4(4)$ & $0(0)$ & 10 \\
\hline Bacillus cereus & $6(1)$ & $2(2)$ & $0(0)$ & 8 \\
\hline $\begin{array}{l}\text { Staphylococcus } \\
\text { enterotoxin }\end{array}$ & $4(1)$ & $0(0)$ & $1(2)$ & 5 \\
\hline Hepatitis & $2(0)$ & $3(3)$ & $0(0)$ & 5 \\
\hline Other† & $16(3)$ & $1(1)$ & $1(2)$ & 18 \\
\hline Total & 632 & 109 & 63 & 804 \\
\hline \multicolumn{5}{|l|}{ Food category } \\
\hline Fish & $57(24)$ & $4(16)$ & $3(17)$ & 64 \\
\hline Molluscs & $38(16)$ & $0(0)$ & $1(6)$ & 39 \\
\hline Chicken & $26(11)$ & $1(4)$ & $1(6)$ & 28 \\
\hline Vegetable row crops & $18(8)$ & $5(20)$ & $2(11)$ & 25 \\
\hline Beef & $21(9)$ & $2(8)$ & $0(0)$ & 23 \\
\hline Grains/beans & $20(9)$ & $2(8)$ & $0(0)$ & 22 \\
\hline Pork & $16(7)$ & $1(4)$ & $2(11)$ & 19 \\
\hline Eggs & $16(7)$ & $0(0)$ & $1(6)$ & 17 \\
\hline Sprouts & $1(0)$ & $5(20)$ & $1(6)$ & 7 \\
\hline Fruits & $5(2)$ & $0(0)$ & $1(6)$ & 6 \\
\hline Seeded vegetables & $2(1)$ & $2(8)$ & $1(6)$ & 5 \\
\hline Other: & $15(6)$ & $3(12)$ & $5(28)$ & 23 \\
\hline Total & 235 & 25 & 18 & 278 \\
\hline
\end{tabular}

* Other (e.g. mall food court, stand-alone deli, banquet) or unknown restaurant type.

$\dagger$ Other confirmed etiologies were amnesic shellfish poisoning $(n=1)$, Cyclospora $(n=2)$, Enterococcus $(n=1)$, Giardia $(n=1)$, Listeria $(n=1)$, other chemicals and toxins not otherwise specified $(n=1)$, pesticides $(n=2)$, sapovirus $(n=2)$, and Trichinella $(n=1)$.

$\$$ Other outbreak food categories were crustaceans $(n=3)$, dairy $(n=3)$, fungi $(n=1)$, herbs $(n=1)$, nuts/seeds $(n=1)$, other meat or poultry not otherwise specified $(n=6)$, root/ underground $(n=4)$, and turkey $(n=4)$.

inherent difficulty in determining the causative food category in a complex food consumed by many people. In some outbreaks, more than one food category may be responsible for illness (i.e. contamination of several food items by ill workers, or crosscontamination).

Overall, over $70 \%$ of outbreaks were due to animalbased foods (meat and seafood items). Animal-based foods were also more commonly implicated in sitdown restaurants (67\% of outbreaks) than fast food restaurants (32\% of outbreaks). Many animal-based food types are likely inherently contaminated before consumption and temperature abuse can lead to bacterial proliferation and toxin production. Appropriate cooking practices, including cooking to the appropriate internal temperature and limiting time at room temperature are imperative to decrease pathogen burden or toxin production before serving.

Nearly half of restaurant-associated outbreaks were caused by norovirus, including most food workerassociated outbreaks. Detection of norovirus outbreaks has increased since the 1990s, likely due in part to improved and more widely used molecular diagnostics, including real-time reverse transcriptionpolymerase chain reaction assays and sequence analysis [18, 19]. Norovirus outbreaks were also larger than those caused by other pathogens. This is likely due in part to norovirus' high infectivity and low infectious dose (as few as 18 viral particles may cause illness) [20]. Norovirus was the most common aetiology in outbreaks linked to vegetable row crops, foods that are commonly eaten raw and may not undergo a heat step to kill pathogens. Outbreaks due to food contaminated with norovirus during production (i.e. before arriving at the restaurant) are rarely identified $[19,21]$. Consistently, our study found that most restaurant-associated norovirus outbreaks were associated with food worker health and hygiene lapses during food preparation or serving. A study reported that restaurants with certified kitchen managers have fewer food contamination events and fewer norovirus outbreaks [22], suggesting that this may be an important intervention.

Scombroid toxin (histamine) was the third most common aetiology identified and was most commonly associated with consumption of fish. Although the median outbreak size involving scombroid toxin was small, it is likely that illness from scombroid toxin is under-recognized since the clinical presentation is similar to an allergy [23]. Cooking contaminated foods does not destroy histamine [23], highlighting the importance of proper handling at the source. Over $85 \%$ of fish consumed in the United States is imported [24], and ensuring immediate freezing of 
raw fish after initial catch and proper storage during transport is crucial to prevent foodborne illness.

Norovirus, B. cereus, Staphylococcus aureus enterotoxin, and $C$. perfringens were the most common suspect aetiologies in restaurant-associated foodborne disease outbreaks. Since most outbreaks caused by these pathogens are short and illness is self-limited, it is often difficult to confirm the aetiology if ill persons do not seek care or if clinical specimens are not tested. In these instances, epidemiologists may assess the clinical syndrome, incubation period, food category, and outbreak setting and designate a suspect aetiology [25].

We found that more outbreaks occurred in sit-down restaurants than fast-food restaurants. There may be several explanations for this observation. First, different food types are prepared differently, for example, sit-down restaurants traditionally have a 'cook-toorder' option in comparison to standard cooking protocols in fast-food restaurants. 'Cook-to-order' food may be more prone to preparation errors, predisposing consumers to foodborne illness. Second, a customer may be more likely to consume raw or undercooked products at a sit-down restaurant, including raw fish, oysters, beef, or eggs. Third, outbreaks in sit-down restaurants might be more likely to be detected because food is usually consumed in group settings, thus more easily allowing ill persons to be identified and linked epidemiologically. Last, many fast-food restaurants have standardized cooking and supplier guidelines as a result of previous high-profile outbreaks; a decrease in the number of outbreaks in this setting may be a direct result of practice improvements.

In 2009 , the surveillance system for foodborne disease outbreaks transitioned to a new electronic reporting platform and subsequently the total number of foodborne disease outbreaks decreased. A survey suggested that this overall decline in foodborne outbreaks was due to decreased resources available for outbreak detection during the influenza $\mathrm{A}(\mathrm{H} 1 \mathrm{~N} 1)$ epidemic and a surveillance artifact [26], given that the percentage of aetiologies and food categories did not change. In our study, the percentage of foodborne outbreaks that were restaurant-associated outbreaks declined annually since 2002 , but has averaged $55 \%$ throughout the study period. Also, the percentage of illnesses associated with restaurant-associated foodborne outbreaks did not change dramatically over the study period (range 7-9\%). The decrease in restaurantassociated outbreaks may be due to improved food handling practices and improved restaurant guidance to prevent foodborne illness or more outbreaks in multiple states are being identified as part of a single, multistate outbreak.

This study has a few limitations. The surveillance system relies on reporting and outbreak investigations by state, local, and territorial public health departments. Changes in the surveillance system, described above, may have contributed to the decrease in the number of outbreaks reported to CDC the health departments that year. Restaurant-related regulations and resources to perform outbreak investigations vary by state, and within a state can vary by jurisdiction. Results might have been influenced by states that receive more funding or resources or have larger populations. Restaurant-associated outbreaks may also be inherently more likely to be reported than other outbreaks.

Knowledge of the foods, aetiologies, and contributing factors that result in restaurant outbreaks can help guide efforts to prevent foodborne illness. Given that the majority of outbreaks were in sit-down restaurants and involved food preparation practices in the restaurant, more work needs to be done to address this issue. Emphasis must be placed on continued education, including refresher trainings for kitchen and serving staff including demonstrations of food-safety knowledge, effective management and appropriate restaurant practices oversight including having a trained manager on duty at all times, implementation of employee health controls including policies during illness and an emphasis on appropriate handwashing, and strict adherence to all food code guidelines.

\section{ACKNOWLEDGEMENTS}

We acknowledge the local, state, and territorial public health departments who report their outbreaks to CDC and the FDOSS surveillance team for their database management and expertise. The findings and conclusions in this report are those of the authors and do not necessarily represent the official position of CDC. This study received no financial support.

\section{DECLARATION OF INTEREST}

None.

\section{REFERENCES}

1. Scallan E, et al. Foodborne illness acquired in the United States - major pathogens. Emerging Infectious Diseases 2011; 17: 7-15. 
2. Centers for Disease Control and Prevention. Surveillance for foodborne disease outbreaks - United States, 19982008. Morbidity and Mortality Weekly Report 2013; 62: $1-34$.

3. Hoffman S, Maculloch B, Batz M. Economic burden of major foodborne illnesses acquired in the United States, EIB-140, United States Department of Agriculture, Economic Research Service (http://www.ers.usda.gov/ media/1837791/eib140.pdf). Accessed 15 September 2015.

4. Centers for Disease Control and Prevention. Surveillance for foodborne disease outbreaks, United States, 2013 (http://www.cdc.gov/foodsafety/pdfs/foodborne-diseaseoutbreaks-annual-report-2013-508c.pdf). Accessed 8 December 2015.

5. Sumner S, et al. factors associated with food workers working while experiencing vomiting or diarrhea. Journal of Food Protection 2011; 74: 215-220.

6. National Restaurant Association. 2015 Restaurant industry pocket factbook (http://www.restaurant.org/ Downloads/PDFs/News-Research/research/Factbook2015_ LetterSize-FINAL.pdf). Accessed 15 September 2015.

7. U.S. Department of Health and Human Services. Food Code (http://www.fda.gov/downloads/Food/Guidance Regulation/RetailFoodProtection/FoodCode/UCM374510. pdf). Accessed 15 September 2015.

8. Centers for Disease Control and Prevention. National Outbreak Reporting System (http://www.cdc.gov/nors/ about.html). Accessed 10 September 2015.

9. Centers for Disease Control and Prevention. Interagency Food Safety Analystics Collaboration (IFSAC) (http:// www.cdc.gov/foodsafety/ifsac/projects/food-categorizationscheme.html). Accessed 18 September 2015.

10. Centers for Disease Control and Prevention. Guide to confirming an etiology in a foodborne disease outbreak (http://www.cdc.gov/foodsafety/outbreaks/investigatingoutbreaks/confirming_diagnosis.html). Accessed 21 June 2016.

11. Centers for Disease Control and Prevention. National outbreak reporting system guidance document (http:// www.cdc.gov/outbreaknet/pdf/NORS_Guidance_5213_ 06232009(compliant).pdf). Accessed 27 September 2015.

12. Green L, Selman C. Factors impacting food workers' and managers' safe food preparation practices: a qualitative study. Food Protection Trends 2005; 25: 981-990.
13. DeBess EE, et al. Food handler assessment in Oregon. Foodborne Pathogenesis and Disease 2009; 6: 329-335.

14. Green L, et al. Factors related to food workers hand hygiene practices. Journal of Food Protection 2007; 70: 661-666.

15. Green L, et al. Food service workers self-reported food preparation practices: an EHS-Net study. International Journal of Hygiene and Environmental Health 2005; 208: 27-35.

16. Strohbehn C, et al. Hand washing frequencies and procedures used in retail food services. Journal of Food Protection 2008; 71: 97-106.

17. Norton DM, et al. Managerial practices regarding workers working while ill. Journal of Food Protection 2015; 78: 187-195.

18. Centers for Disease Control and Prevention. Diagnostic methods for norovirus (http://www.cdc.gov/norovirus/ lab-testing/diagnostic.html) Accessed 22 December 2015.

19. Hall AJ, et al. Epidemiology of foodborne norovirus outbreaks, United States, 2001-2008. Emerging Infectious Diseases 2013; 18: 1566-1573.

20. Teunis PF, et al. Norwalk virus: how infectious is it? Journal of Medical Virology 2008; 80: 1468-1476.

21. Hall AJ, et al. Vital signs: foodborne norovirus outbreaks - United States, 2009-2012. Morbidity and Mortality Weekly Report 2014; 63: 491-495.

22. Hedberg CW, et al. Systematic environmental evaluations to identify food safety differences between outbreak and nonoutbreak restaurants. Journal of Food Protection 2006; 69: 697-702.

23. Food and Drug Administation. Scombrotoxin poisoning and decomposition (http://www.fda.gov/food/foodborneillnesscontaminants/buystoreservesafefood/ucm335658.htm).

24. National Oceanic and Atmospheric Administration. Commercial fisheries statistics (http://www.st.nmfs. noaa.gov/commercial-fisheries/fus/fus14/index). Accessed 31 August 2016.

25. Bennett SD, Walsh K, Gould LH. Foodborne Disease Outbreaks caused by Bacillus cereus, Clostridium perfringens, and Staphylococcus aureus, United States, 1998-2008. Clinical Infectious Diseases 2013; 57: 425433.

26. Imanishi M, et al. Factors Contributing to Decline in Foodborne Disease Outbreak Reports, United States. Emerging Infectious Diseases 2014; 20: 1551-1553. 


\section{APPENDIX A}

Categories used for analysis of contributing factors in restaurant-associated foodborne disease outbreaks, Foodborne Disease Outbreak Surveillance System, 1998-2013* ( $n=6907$ contributing factors)

\begin{tabular}{|c|c|c|c|}
\hline Category & $\begin{array}{l}\text { Contributing factors } \\
1998-2008\end{array}$ & $\begin{array}{l}\text { Contributing factors } \\
\text { 2009-2012 }\end{array}$ & $\begin{array}{l}\text { No. of } \\
\text { outbreaks } \\
(\%)\end{array}$ \\
\hline \multirow{3}{*}{$\begin{array}{l}\text { Food worker health \& } \\
\text { hygiene }\end{array}$} & $\begin{array}{l}\text { Bare-handed contact by handler/worker/ } \\
\text { preparer (e.g. with ready-to-eat food) }\end{array}$ & $\begin{array}{l}\text { Bare-hand contact by a food handler/ } \\
\text { worker/preparer who is suspected to be } \\
\text { infectious }\end{array}$ & $1451(62)$ \\
\hline & $\begin{array}{l}\text { Handling by an infected person or carrier } \\
\text { of pathogen (e.g. Staphylococcus, } \\
\text { Salmonella, norovirus) }\end{array}$ & $\begin{array}{l}\text { Other mode of contamination (excluding } \\
\text { cross-contamination) by a food handler/ } \\
\text { worker/preparer who is suspected to be } \\
\text { infectious }\end{array}$ & $1073(46)$ \\
\hline & $\begin{array}{l}\text { Glove-handed contact by handler/worker/ } \\
\text { preparer (e.g. with ready-to-eat food) }\end{array}$ & $\begin{array}{l}\text { Glove-hand contact by a food handler/ } \\
\text { worker/preparer who is suspected to be } \\
\text { infectious }\end{array}$ & $463(20)$ \\
\hline
\end{tabular}

Any of the above

Raw product/ingredient contaminated by Contaminated raw product - food was pathogens from animal or environment (e.g. Salmonella Enteriditis in egg, norovirus in shellfish, E. coli in sprouts)

Contamination of food before reaching the restaurant
Toxic substance part of tissue (e.g. ciguatera)

Ingestion of contaminated raw products (e.g. raw shellfish, produce, eggs)

Obtaining foods from polluted sources (e.g. shellfish) intended to be consumed after a kill step

$396(52)$

Toxic substance part of the tissue

Contaminated raw product - food was intended to be served raw or undercooked/under processed

Foods originating from sources shown to 22 (3) be contaminated or polluted (such as a growing field or harvest area)
Improper adherence of approved plan to use time as a public health control

Inadequate thawing of frozen products (e.g. room thawing)

Insufficient thawing, followed by insufficient cooking (e.g. frozen turkey)

Cross-contamination from raw ingredient of animal origin (e.g. raw poultry on the cutting board)

Preparing foods a half day or more before serving (e.g. banquet preparation a day in advance)

Insufficient time and/or temperature during hot holding (e.g. malfunctioning equipment, too large a mass of food)
Food preparation practices that support proliferation of pathogens (during food preparation)

Foods contaminated by a non-food handler/worker/preparer who is suspected to be infectious

Cross-contamination of ingredients (cross-contamination does not include ill food workers)

No attempt was made to control the temperature of implicated food or the length of time food was out of temperature control (during food service or display of food)

Improper hot holding due to 
APPENDIX A (cont.)

\begin{tabular}{|c|c|c|c|}
\hline Category & $\begin{array}{l}\text { Contributing factors } \\
1998-2008\end{array}$ & $\begin{array}{l}\text { Contributing factors } \\
\text { 2009-2012 }\end{array}$ & $\begin{array}{l}\text { No. of } \\
\text { outbreaks } \\
(\%)\end{array}$ \\
\hline & $\begin{array}{l}\text { Insufficient time and/or temperature } \\
\text { during initial cooking/heat processing } \\
\text { (e.g. roasted meats/poultry, canned } \\
\text { foods, pasteurization) }\end{array}$ & $\begin{array}{l}\text { Insufficient time and/or temperature } \\
\text { control during initial cooking/heat } \\
\text { processing }\end{array}$ & $382(13)$ \\
\hline \multirow[t]{14}{*}{$\begin{array}{l}\text { Food handling and } \\
\text { preparation practices } \\
\text { in the restaurant }\end{array}$} & $\begin{array}{l}\text { Inadequate cold-holding temperatures } \\
\text { (e.g. refrigerator inadequate/not } \\
\text { working, ice holding inadequate) }\end{array}$ & $\begin{array}{l}\text { Improper cold holding due to } \\
\text { malfunctioning refrigeration equipment }\end{array}$ & $311(10)$ \\
\hline & $\begin{array}{l}\text { Insufficient time and/or temperature } \\
\text { during reheating (e.g. sauces, roasts) }\end{array}$ & $\begin{array}{l}\text { Insufficient time and/or temperature } \\
\text { during reheating }\end{array}$ & $303(10)$ \\
\hline & $\begin{array}{l}\text { Storage in contaminated environment B } \\
\text { leads to contamination of vehicle (e.g. } \\
\text { store room, refrigerator) }\end{array}$ & Storage in contaminated environment & $268(9)$ \\
\hline & & $\begin{array}{l}\text { Improper cold holding due to an improper } \\
\text { procedure or protocol }\end{array}$ & $110(4)$ \\
\hline & $\begin{array}{l}\text { Allowing foods to remain at room or } \\
\text { warm outdoor temperature for several } \\
\text { hours (e.g. during preparation or holding } \\
\text { for service) }\end{array}$ & $\begin{array}{l}\text { Improper hot holding due to improper } \\
\text { procedure or protocol }\end{array}$ & $72(2)$ \\
\hline & $\begin{array}{l}\text { Slow cooling (e.g. deep containers or large } \\
\text { roasts) }\end{array}$ & Improper/slow cooling & $61(2)$ \\
\hline & & $\begin{array}{l}\text { Insufficient or improper use of chemical } \\
\text { processes designed for pathogen } \\
\text { destruction }\end{array}$ & $44(1)$ \\
\hline & $\begin{array}{l}\text { Prolonged cold storage for several weeks } \\
\text { (e.g. permits slow growth of } \\
\text { psychrophilic pathogens) }\end{array}$ & Prolonged cold storage & $35(1)$ \\
\hline & $\begin{array}{l}\text { Anaerobic packaging/modified } \\
\text { atmosphere (e.g. vacuum packed fish, } \\
\text { salad in gas flushed bag) }\end{array}$ & $\begin{array}{l}\text { Inadequate modified atmosphere } \\
\text { packaging }\end{array}$ & $7(0)$ \\
\hline & & $\begin{array}{l}\text { Insufficient time and/or temperature } \\
\text { control during freezing }\end{array}$ & $5(0)$ \\
\hline & $\begin{array}{l}\text { Inadequate acidification (e.g. mayonnaise, } \\
\text { tomatoes canned) }\end{array}$ & $\begin{array}{l}\text { Inadequate processing (acidification, } \\
\text { water activity, fermentation) }\end{array}$ & \\
\hline & $\begin{array}{l}\text { Inadequate fermentation (e.g. processed } \\
\text { meat, cheese) }\end{array}$ & & $4(0)$ \\
\hline & $\begin{array}{l}\text { Insufficiently low water activity (e.g. } \\
\text { smoked/salted fish) }\end{array}$ & & \\
\hline & $\begin{array}{l}\text { Insufficient acidification (e.g. home } \\
\text { canned foods) }\end{array}$ & & \\
\hline
\end{tabular}

Any of the above

$2995(43)$

Other source of contamination

Other source of contamination

475 (59)

Other process failures that permit the agent to survive

Other

Other situations that promote or allow microbial growth or toxic production

Toxic container of pipelines (e.g.

Other process failures that permit the

246 (30)

agent to survive

Other situations that promote or allow

$130(16)$

galvanized containers with acid food, copper pipe with carbonated beverages)

Poisonous substance intentionally added (e.g. cyanide or phenolphthalein added microbial growth or toxic production

Toxic container

Poisonous substance intentionally/ to cause illness) 
APPENDIX A (cont.)

\begin{tabular}{|c|c|c|c|}
\hline Category & $\begin{array}{l}\text { Contributing factors } \\
1998-2008\end{array}$ & $\begin{array}{l}\text { Contributing factors } \\
\text { 2009-2012 }\end{array}$ & $\begin{array}{l}\text { No. of } \\
\text { outbreaks } \\
(\%)\end{array}$ \\
\hline & $\begin{array}{l}\text { Addition of excessive quantities of } \\
\text { ingredients that are toxic under these } \\
\text { situations (e.g. niacin poisoning in bread) }\end{array}$ & $\begin{array}{l}\text { Addition of excessive quantities of } \\
\text { ingredients that are toxic in large } \\
\text { amounts }\end{array}$ & $4(1)$ \\
\hline & $\begin{array}{l}\text { Poisonous or physical substance } \\
\text { accidentally/incidentally added (e.g. } \\
\text { sanitizer or cleaning compounds }\end{array}$ & $\begin{array}{l}\text { Poisonous substance accidentally/ } \\
\text { inadvertently added }\end{array}$ & $2(0)$ \\
\hline
\end{tabular}

Any of the above

$807(12)$

* Contributing factor definitions were revised in 2009 and outbreaks may be listed under more than one factor.

\section{APPENDIX B}

Foodborne disease outbreaks associated with a restaurant setting, Foodborne Disease Outbreak Surveillance System, $1998-2013(n=9788)$

\begin{tabular}{|c|c|}
\hline $\begin{array}{l}\text { Outbreaks with a particular food } \\
\text { implicated } \\
\qquad(n=4102,42 \%)\end{array}$ & $\begin{array}{l}\text { Outbreaks for which an aetiology } \\
\text { was confirmed or suspected } \\
\qquad(n=5528,57 \%)\end{array}$ \\
\hline $\begin{array}{l}\text { Single food category } \\
\qquad(n=1175,43 \%)\end{array}$ & $\begin{array}{c}\text { Confirmed } \\
(n=3072,56 \%)\end{array}$ \\
\hline $\begin{array}{l}\text { Multiple food categories } \\
\qquad(n=2327,57 \%)\end{array}$ & $\begin{array}{l}\text { Suspected } \\
(n=2978,44 \%)\end{array}$ \\
\hline
\end{tabular}

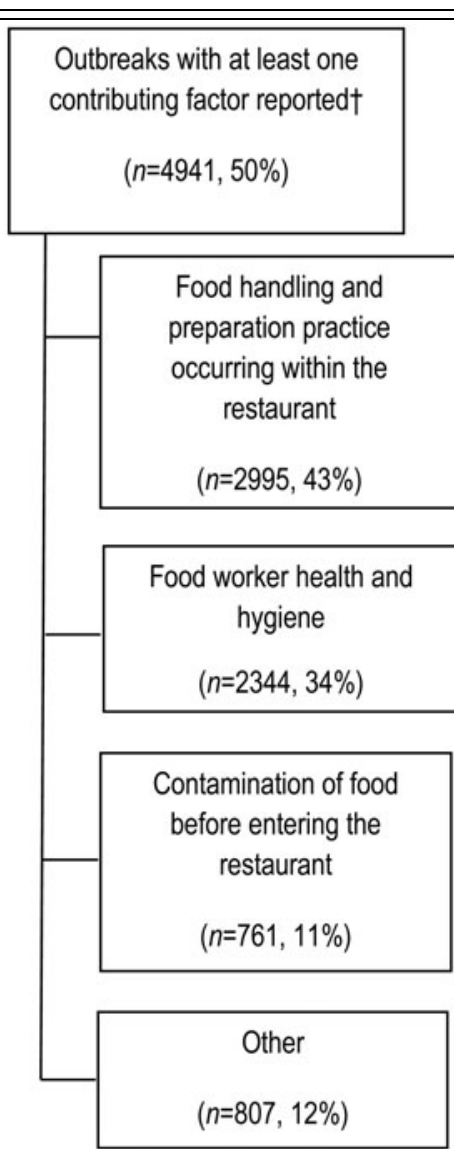

\footnotetext{
* Foods were classified according to the Interagency Food Safety Analytics Collaboration's (IFSAC) scheme and include the following categories: dairy, eggs, fish, fruits, fungi, game, grains-beans, herbs, meat (e.g. beef, pork), oils/sugars, nuts/seeds, poultry (e.g. chicken, turkey), shellfish (e.g. crustaceans, molluscs), sprouts, vegetables (e.g. root-underground, seeded, vegetable row crops), and other poultry or meat.

$\dagger$ More than one contributing factor categories may be reported.
} 